\title{
Тяжелые металлы в донных отложениях озера Фара, Западный Шпицберген
}

Даувальтер В.А. ${ }^{1}$, Мещеряков Н.И. ${ }^{2}$, Усягина И.С. ${ }^{2}$, Духно Г.Н. ${ }^{2}$, Шарин В.В. ${ }^{3,4}$, Слуковский $3 . И .{ }^{1,5}$, Денисов Д.Б. ${ }^{1}$

${ }^{1}$ Институт проблем промышленной экологии Севера КНЦ PAH, Anamumbl, v.dauvalter@ksc.ru

${ }^{2}$ Мурманский морской биологический институт РАН, Мурманск

${ }^{3}$ Полярная морская геологоразведочная экспедищия, Санкт-Петербург - Ломоносов

${ }^{4}$ Санкт-Петербургский государственный университет, Санкт-Петербург

${ }_{5}^{5}$ Институт геологии КарНЦ РАН, Петрозаводск, slukovsky87@gmail.com

Аннотация. По результатам комплексных исследований донных отложений была проведена оценка современного экологического состояния озера Фара, Западный Шпицберген. Установлено увеличение содержания $\mathrm{Pb}$ и As в поверхностных слоях донных отложений в 4 и 3 раза соответственно по сравнению с фоновым содержанием, что объясняется многолетней добычей угля в близлежащем шахтерском поселке. В целом степень загрязнения этого арктического озера по 8 исследуемым тяжелым металлам ( $\mathrm{Ni}, \mathrm{Cu}, \mathrm{Co}, \mathrm{Zn}, \mathrm{Pb}, \mathrm{Cd}$, $\mathrm{Hg}, \mathrm{As})$ можно оценить как умеренное.

Ключевые слова: Арктика, Шпицберген, озера, донные отложения, тяжелые металлы, гранулометрический состав, органическое вещество.

\section{Heavy metals in sediments of Lake Fara, West Svalbard}

\author{
Dauvalter V.A. ${ }^{1}$, Meshcheryakov N.I. ${ }^{2}$, Usyagina I.S. ${ }^{2}$, Dukhno G.N. ${ }^{2}$, Sharin V.V. ${ }^{3,4}$, Slukovskii Z.I. ${ }^{1,5}$, \\ Denisov D.B. ${ }^{1}$ \\ ${ }^{1}$ Institute of North Industrial Ecology Problems Kola SC RAS, Apatity,v.dauvalter@ksc.ru \\ ${ }^{2}$ Murmansk Marine Biological Institute RAS, Murmansk, Russia \\ ${ }^{3}$ Polar Marine Geological Expedition, St. Petersburg - Lomonosov, Russia \\ ${ }^{4}$ Saint Petersburg State University, Saint Petersburg, Russia \\ ${ }^{5}$ Institute of Geology of Karelian Research Centre of RAS, Petrozavodsk, slukovsky87@gmail.com
}

\begin{abstract}
Based on the results of comprehensive studies of sediments, an assessment of the current ecological state of Lake Fara, West Spitsbergen, was carried out. An increase in the content of $\mathrm{Pb}$ and As in the surface sediment layers was established by 4 and 3 times, respectively, compared to the background content, which is explained by the long-term coal mining. In general, the degree of contamination of this Arctic lake for 8 investigated heavy metals $(\mathrm{Ni}, \mathrm{Cu}, \mathrm{Co}, \mathrm{Zn}, \mathrm{Pb}, \mathrm{Cd}, \mathrm{Hg}, \mathrm{As})$ can be assessed as moderate.
\end{abstract}

Key words: Arctic, Spitsbergen, lakes, sediments, heavy metals, particle size distribution, organic matter.

\section{Введение}

Освоение природных ресурсов Арктики в последние годы нарастает ускоренными темпами, поэтому антропогенная нагрузка на арктическую окружающую среду с каждым годом будет только усиливаться. Если еще в начале XX века Арктика оставалась одной из самых нетронутых результатами антропогенной деятельности в мире территорий, то спустя век современное экологическое состояние вызывает озабоченность, в первую очередь, стран, обладающих арктическими территориями (Россия, Канада, Норвегия, Дания, США), так и во всем мире. Это требует необходимость проведения комплексных исследований водных и наземных экосистем Арктики для оценки их состояния. На архипелаге Шпицберген относительно долгая история добычи угля (с начала двадцатого века) заставляет учитывать состояние окружающей среды не только в настоящее время, но и до недавней деятельности человека (Rose et al. 2004). Учитывая сохраняющийся потенциал эксплуатации ископаемого топлива на Шпицбергене (Holte et al. 1996), проведение комплексных экологических исследований на Шпицбергене, как одной из наиболее индустриально освоенных территорий в высоких широтах Арктики, является вдвойне важным. С целью оценки современного экологического 
состояния водных систем промышленно освоенных территорий архипелага Шпицберген сотрудниками нескольких научных организаций России были проведены комплексные исследования донных отложений (ДО) озера Фара, Западный Шпицберген.

\section{Материалы и методы}

Пробы поверхностного слоя (0-2 см) ДО из оз. Фара (норвежское название озера Тенндаммен) были отобраны летом 2018 г. дночерпателем Питерсена на 7 станциях (рис.). Глубина на станциях отбора проб была примерно одинаковой по всему озеру и находилась в пределах 1.5-1.6 м. Для озера характерны округлая форма с радиусом около 250 м и резкий свал глубин недалеко от берега. Ко-

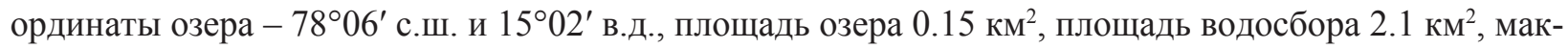
симальная глубина - 2.5 м. В геологическом строении водосбора озера принимают участие современные морские отложения, а также песчаники и глинистые сланцы палеоцен-эоценового возраста (Boyle et al, 2004). В 10 км от озера на северо-восток расположен российский шахтерский поселок Грумант. Свое название поселок получил из-за старого поморского названия Шпицбергена - Грумант. В поселке Грумант с 1931 г. Государственным трестом «Арктикуголь» производилась добыча угля, но из-за отсутствия глубоководного порта его погрузка на суда происходила в порту Колсбей, куда вела железная дорога. В течение 30 лет оз. Фара испытывало довольно интенсивную антропогенную нагрузку. За время своего существования трест «Арктикуголь» добыл на руднике Грумант 2 млн. т угля. В 1961 г. было принято решение о консервации рудника.

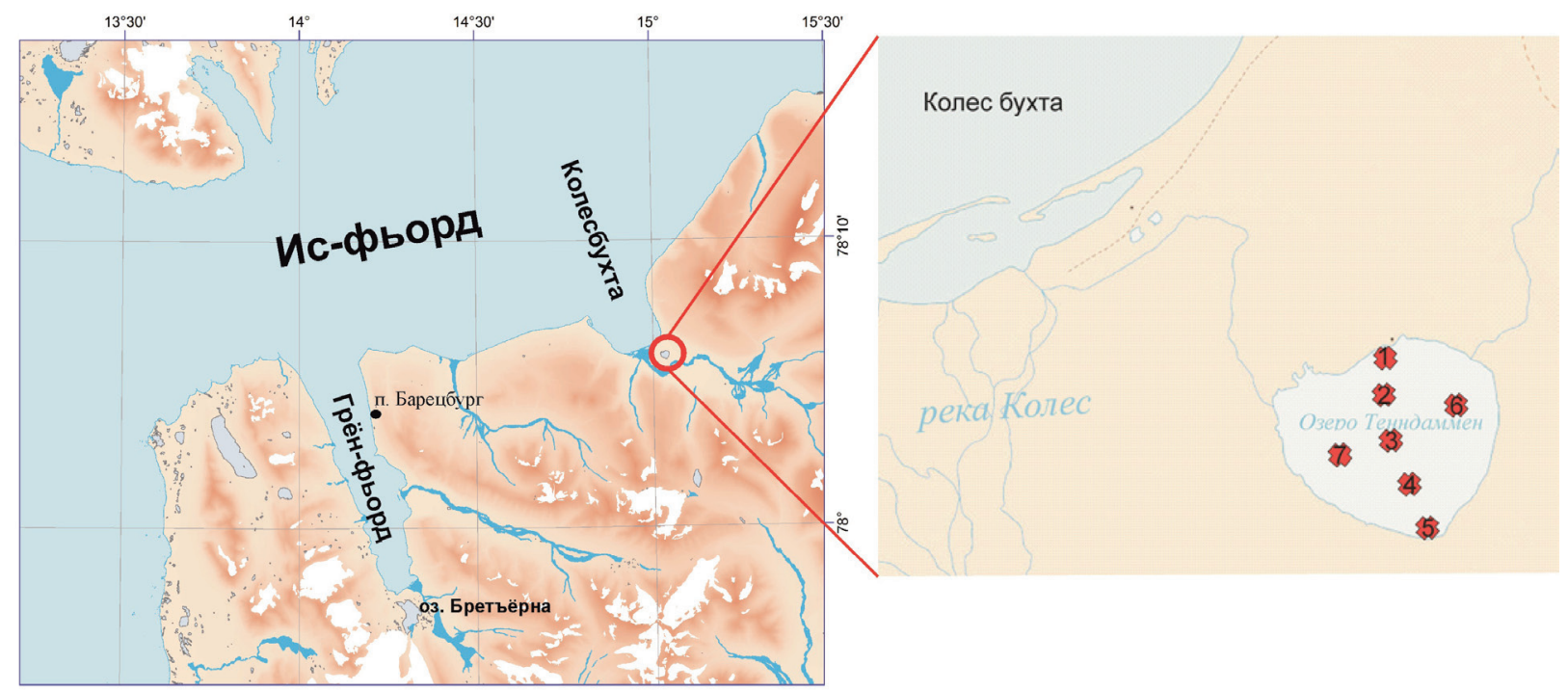

Рис. Карта-схема станций отбора проб донных отложений в озере Фара (Тенндаммен).

Fig. Map of sampling stations of sediments in Lake Fara (Tenndammen).

В пробах ДО оз. Фара в ММБИ РАН проведен гранулометрический анализ, определены потери при прокаливании (ППП), как косвенный показатель содержания органического материала. Содержание тяжелых металлов ( $\mathrm{TM}$ - Ni, $\mathrm{Cu}, \mathrm{Co}, \mathrm{Zn}, \mathrm{Cd}, \mathrm{Pb}, \mathrm{As}, \mathrm{Hg}$ ) определялось методом массспектрометрии с индуктивно связанной плазмой (ICP-MS) в центре коллективного пользования ИППЭС КНЦ РАН по единым методикам. Методика отбора и определение химического состава ДО подробно описаны ранее (Даувальтер, 2012; Методы..., 2019).

Оценка современного экологического состояния оз. Фара проводилась по методике Л. Хокансона (Håkanson, 1980) с помощью коэффициента загрязнения $\left(\mathrm{C}_{\mathrm{f}}\right)$ каждого загрязняющего ТМ ( $\mathrm{Ni}, \mathrm{Cu}, \mathrm{Co}, \mathrm{Zn}, \mathrm{Pb}, \mathrm{Cd}, \mathrm{Hg}$, As). Значения $\mathrm{C}_{\mathrm{f}}$ находили путем деления концентраций ТМ в поверхностном 1-см слое на фоновое значение для данного ТМ, определенное как среднее фоновое значение в ДО озер Мурманской области (Kashulin et al., 2017) (табл. 2). Степень загрязнения (С $\mathrm{C}_{\mathrm{d}}$ ) определяли суммированием всех значений $\mathrm{C}_{\mathrm{f}}$ для восьми ТМ для данной станции. В этом подходе при- 
держивались следующей классификации $\mathrm{C}_{\mathrm{f}}^{\mathrm{i}}$ : $\mathrm{C}_{\mathrm{f}}{ }^{\mathrm{i}}<1-$ низкий; $1 \leq \mathrm{C}_{\mathrm{f}}{ }^{\mathrm{i}}<3$ - умеренный; $3 \leq \mathrm{C}_{\mathrm{f}}^{\mathrm{i}}<6$ - значительный; $\mathrm{C}_{\mathrm{f}}^{\mathrm{i}} \geq 6$ - высокий коэффициент загрязнения. Аналогично, при характеристике $\mathrm{C}_{\mathrm{d}}$, придерживались классификации, из расчета, что суммируем значения $\mathrm{C}_{\mathrm{f}}$ по 8 элементам: $\mathrm{C}_{\mathrm{d}}<8$ - низкая; $8 \leq \mathrm{C}_{\mathrm{d}}<16$ - умеренная; $16 \leq \mathrm{C}_{\mathrm{d}}<32$ - значительная; $\mathrm{C}_{\mathrm{d}} \geq 32$ - высокая степень загрязнения (Даувальтер, 2012).

\section{Результаты и обсуждение}

По результатам гранулометрического анализа установлено, что в ДО оз. Фара в целом преобладают пелитовая и алевритовая фракции с примесью разнозернистого песка (Даувальтер и др., 2019). В ДО со станции 5 (южный мелкий берег) присутствуют включения гравийно-галечных зерен. В ДО озера присутствуют частички угля, особенно на станции 1 (северный берег). Несмотря на небольшую глубину озера и короткий безледный период, в нем происходит сортировка частиц ДО по гранулометрическим фракциям в результате, главным образом, волновой деятельности, выражающейся в том, что в центральной части озера (станции 2-4, а также 6) преобладает тонкодисперсная пелитовая и алевритовая фракция (размером $<0.01$ мм), доля которой составляет на этих станциях от 55 до 84 \%. На этих станциях практически отсутствуют фракции грубого и крупного песка, появляется незначительная доля среднего и мелкого песка (первые единицы процента), увеличивается доля алевритовой фракции (от 10 до 40 \%). В ДО станций, расположенных ближе к берегу, уменьшается доля пелитовой фракции, но увеличивается алевритовой и псаммитовой. Таким образом, распределение гранулометрических типов осадков в оз. Фара соответствует идеальной схеме течения процессов сортировки и осаждения материала, при котором от периферии бассейна к его центру идет постепенное уменьшение размера частиц, слагающих осадки (Страхов и др., 1945; Håkanson, 1980).

Значения ППП в ДО оз. Фара невелики для северных и арктических озер (Даувальтер, 2012) и находятся в небольшом диапазоне от 5.4 до 8.8 \%, причем максимальная величина зафиксирована в прибрежных станциях 1 и 7 (табл. 1), что нехарактерно для озерных отложений, где, как правило, в тонкодисперсных отложениях отмечаются более высокие величины ППП (Даувальтер, 2012). Наименьшее значение ППП зафиксировано на станции 5, в ДО которой присутствует довольно большая доля гравийно-галечных зерен (17 \%). Незначительные величины ППП могут говорить о неактивной биологической деятельности в самом озере (за счет чего образуется автохтонный органический материал) и на территории его водосбора (аллохтонный материал), что характеризует суровые арктические условия.

Таблица 1. Гранулометрический состав и потери веса при прокаливании (ППП) донных отложений озера Фара (Тенндаммен), \%, значения коэффициента корреляции ППП и содержания гранулометрических фракций (r).

Table 1. Granulometric composition and loss on ignition (LOI) of sediments of Lake Fara (Tenndammen), \%, the values of the correlation coefficient of the LOI and particle size fractions ( $\mathrm{r}$ ).

\begin{tabular}{|c|c|c|c|c|c|c|c|c|c|}
\hline \multirow{2}{*}{ Станции } & \multirow{2}{*}{$\begin{array}{c}\text { ППП } \\
\text { LOI }\end{array}$} & $>2$ & $1-2$ & $1-0.5$ & $0.5-0.25$ & $0.25-0.1$ & $0.1-0.05$ & $0.05-0.01$ & $<0.01$ \\
\hline & & \multicolumn{8}{|c|}{ MM } \\
\hline 1 & 8.8 & 1.7 & 3.0 & 14.9 & 10.7 & 12.3 & 8.9 & 14.0 & 34.5 \\
\hline 2 & 7.5 & 0.0 & 0.1 & 0.3 & 1.2 & 4.5 & 2.4 & 7.5 & 84.0 \\
\hline 3 & 6.7 & 0.0 & 0.1 & 1.3 & 1.2 & 4.2 & 6.8 & 18.1 & 68.3 \\
\hline 4 & 5.5 & 0.0 & 0.0 & 0.0 & 0.2 & 1.0 & 4.1 & 39.5 & 55.2 \\
\hline 5 & 5.4 & 16.7 & 7.2 & 4.0 & 2.2 & 2.6 & 7.0 & 33.1 & 27.2 \\
\hline 6 & 6.0 & 0.0 & 0.1 & 0.5 & 1.0 & 5.3 & 2.1 & 18.5 & 72.5 \\
\hline 7 & 8.8 & 0.0 & 0.0 & 0.6 & 1.8 & 10.9 & 9.7 & 49.5 & 27.5 \\
\hline \multicolumn{2}{|c|}{$\mathrm{r}$} & -0.42 & -0.24 & 0.46 & 0.59 & 0.92 & 0.57 & -0.08 & -0.25 \\
\hline
\end{tabular}

Содержание большинства ТM (Cu, Ni, Co, $\mathrm{Zn}, \mathrm{Cd}, \mathrm{Hg})$ в ДО оз. Фара (средние значения 31, $39,16,75,0.14,0.037$ мкг/г соответственно) сопоставимо со средними фоновыми концентрация- 
ми озер Мурманской области (Kashulin et al., 2017). Превышение фоновых концентраций зафиксировано для $\mathrm{Pb}$ и As в среднем в 4 и 3 раза соответственно, среднее содержание которых составляет 18 и 9.1 мкг/г. Ранее проведенными исследованиями в оз. Тенндаммен было установлено, что среднее содержание $\mathrm{Cu}, \mathrm{Pb}$ и $\mathrm{Zn}$ в колонке ДО составляет 24, 21 и 78 мкг/г соответственно (Boyle et al, 2004), что не намного отличается от полученных нами результатов. На станции 1 зафиксировано превышение фоновых концентраций более чем в 2 раза для $\mathrm{Cu}$ и Ni. B целом по результатам определения содержания 8 исследованных ТМ степень загрязнения оз. Фара оценивается как умеренная со значительными коэффициентами загрязнения по $\mathrm{Pb}$ и As.

Проведенный корреляционный анализ показал достоверную высокую связь органического материала с мелко-песчаной фракцией $(\mathrm{r}=0.92)$, что также нехарактерно для озерных отложений. Менее значимые величины коэффициента корреляции были выявлены для средне-песчаной и алевритовой фракций ( $\mathrm{r}=0.59$ и 0.57 соответственно). Установлена достоверная высокая связь содержания $\mathrm{Cu}$ и $\mathrm{Ni}(\mathrm{r}=0.97$ и 0.95 соответственно) с органическим материалом, что говорит о нахождении этих металлов в составе органических соединений. Вышеперечисленные металлы имеют также высокие коэффициенты корреляции с песчаными фракциями 0.1-1 мм (r=0.74-0.97).

Таблица 2. Концентрации ТМ в ДО оз. Фара (в числителе), значения коэффициента загрязнения (Cf, в знаменателе), степени загрязнения (Cd, последняя колонка в таблице) и средние фоновые концентрации ТМ в ДО озер Мурманской области (Kashulin et al., 2017).

Table 2. Concentrations of heavy metals in the sediments of Lake Fara (in the numerator), the values of the contamination factor (Cf, in the denominator), degree of contamination (Cd) and the average background concentrations of heavy metals in the lake sediments of the Murmansk region (Kashulin et al., 2017).

\begin{tabular}{|c|c|c|c|c|c|c|c|c|c|}
\hline Станции & $\mathrm{Cu}$ & $\mathrm{Ni}$ & Co & $\mathrm{Zn}$ & $\mathrm{Cd}$ & $\mathrm{Pb}$ & As & $\mathrm{Hg}$ & $\mathrm{C}_{\mathrm{d}}$ \\
\hline \multirow{2}{*}{1} & $\underline{59.2}$ & $\underline{59.0}$ & $\underline{12.3}$ & $\underline{61.0}$ & $\underline{0.213}$ & $\underline{13.3}$ & 9.23 & $\underline{0.022}$ & \\
\hline & 2.2 & 2.2 & 1.0 & 0.6 & 0.9 & 3.0 & 2.9 & 0.6 & 13.5 \\
\hline \multirow{2}{*}{2} & 28.1 & $\underline{36.7}$ & 18.1 & 75.9 & $\underline{0.053}$ & 19.9 & $\underline{8.85}$ & $\underline{0.082}$ & \\
\hline & 1.1 & 1.4 & 1.4 & 0.8 & 0.2 & 4.5 & 2.8 & 2.4 & 14.5 \\
\hline \multirow{2}{*}{3} & 27.1 & 37.5 & 17.1 & $\underline{83.6}$ & $\underline{0.185}$ & 19.5 & $\underline{8.06}$ & 0.030 & \\
\hline & 1.0 & 1.4 & 1.3 & 0.9 & 0.8 & 4.4 & 2.5 & 0.9 & 13.2 \\
\hline \multirow{2}{*}{4} & 25.5 & $\underline{34.5}$ & 15.7 & 75.8 & $\underline{0.155}$ & 17.4 & $\underline{7.13}$ & $\underline{0.028}$ & \\
\hline & 1.0 & 1.3 & 1.2 & 0.8 & 0.7 & 3.9 & 2.2 & 0.8 & 11.9 \\
\hline \multirow{2}{*}{5} & $\underline{22.8}$ & $\underline{28.3}$ & 13.1 & $\underline{63.5}$ & $\underline{0.052}$ & $\underline{15.5}$ & $\underline{9.02}$ & $\underline{0.022}$ & \\
\hline & 0.9 & 1.0 & 1.0 & 0.7 & 0.2 & 3.5 & 2.8 & 0.6 & 10.8 \\
\hline \multirow{2}{*}{6} & $\underline{27.0}$ & $\underline{35.9}$ & 17.4 & $\underline{80.3}$ & $\underline{0.152}$ & 20.1 & 10.9 & $\underline{0.042}$ & \\
\hline & 1.0 & 1.3 & 1.4 & 0.8 & 0.7 & 4.6 & 3.4 & 1.2 & 14.4 \\
\hline \multirow{2}{*}{7} & $\underline{28.0}$ & $\underline{37.8}$ & $\underline{15.8}$ & $\underline{83.8}$ & $\underline{0.145}$ & 19.9 & 10.8 & $\underline{0.036}$ & \\
\hline & 1.0 & 1.4 & 1.2 & 0.9 & 0.6 & 4.5 & 3.4 & 1.0 & 14.1 \\
\hline Фон & 26.7 & 27.1 & 12.8 & 95.7 & 0.228 & 4.4 & 3.17 & 0.035 & \\
\hline
\end{tabular}

В толще ДО оз. Болтерскардет, расположенного в 10 км на восток от поселка Грумант, среди исследованных $\mathrm{TM}(\mathrm{Pb}, \mathrm{As}, \mathrm{Cd}, \mathrm{Cu}, \mathrm{Cr}, \mathrm{Co}, \mathrm{Ni}$ и $\mathrm{Sn}$ ) только $\mathrm{Pb}$ показывает значительное увеличение концентраций от нижних к верхним частям колонки (Sun et al., 2006). Обнаружено также увеличение антропогенного потока $\mathrm{Pb}$ в вертикальном распределении. Антропогенные потоки $\mathrm{Pb}$ были относительно низкими до 1945 г., т.е. до конца Второй мировой войны - около 0.7 мкг/ $\mathrm{cm}^{2}$ год. После 1945 г. отмечалось более чем двукратное увеличение потока $\mathrm{Pb}$ со средним значением 1.8 мкг/ $\mathrm{cm}^{2}$ год. В период между 1980-ми и 1990 -ми годами произошло резкое увеличение потока $\mathrm{Pb}$ до среднего значения 5.9 мкг $\mathrm{cm}^{2}$.год. Изменение потоков антропогенного Рb до 1970 г. в оз. Болтерскардет показывает картину, сходную с данными в ледниковых щитах Гренландии (Boutron et al. 1995). Таким образом, в конце XX века в оз. Болтерскардет наблюдается быстро увеличивающаяся тенденция антропогенных потоков $\mathrm{Pb}$. Это говорит о том, что местная антропогенная деятель- 
ность (например, сжигание угля) сыграла важную роль в увеличении антропогенного потока $\mathrm{Pb}$ в последние два десятилетия XX века. Ранее проведенными исследованиями (Rognerud et al., 1998) было также обнаружено, что в поверхностных слоях ДО озер Шпицбергена происходит повышение концентраций $\mathrm{Hg}$ и $\mathrm{Pb}$ по сравнению с ее доиндустриальными содержаниями. Увеличение содержания ТМ в ДО водоемов, вероятно, является результатом загрязнения за счет трансграничного переноса, так и от местных источников. Поэтому необходимы дальнейшие исследования Арктических озер Шпицбергена, очень чувствительных к изменениям состояния окружающей среды и климата.

\section{Выводы}

В ДО оз. Фара в целом преобладают тонкодисперстные пелитовая и алевритовая фракции с примесью разнозернистого песка. В результате определения содержания 8 исследованных ТМ в ДО оз. Фара установлено, что степень загрязнения этого арктического озера можно оценить как умеренное, но значительные коэффициенты загрязнения выявлены для $\mathrm{Pb}$ и As, что является результатом влияния, в первую очередь, многолетней добычи угля в близлежащем шахтерском поселке Грумант. Установлена достоверная высокая связь содержания $\mathrm{Cu}$ и $\mathrm{Ni}$ с органическим материалом, а также с песчаными фракциями.

Работа выполнена в рамках темы НИР №0226-2019-0045, госзадания «Комплексные исследования экосистем фьордов и морей, омывающих архипелаг Шпицберген» (полевые работы, отбор проб, гранулометрический анализ и определение потерь при прокаливании) и частично поддержана из средств грантов РФФИ № 18-05-60125 (пробоподготовка к химическому анализу) и РНФ № 19-77-10007 (определение содержания элементов).

\section{Литература}

1. Даувальтер В.А. Геоэкология донных отложений озер. Мурманск. Изд-во: МГТУ. 2012. 242 c.

2. Даувальтер В.А., Мещеряков Н.И., Усягина И.С., Духно Г.Н., Шарин В.В., Слуковский 3.И. Предварительные результаты исследований донных отложений арктического озера Фара, Западный Шпицберген // Труды Ферсмановской научной сессии ГИ КНЦ РАН. 2019. № 16. С. 121-125. https://doi.org/10.31241/ FNS.2019.16.025.

3. Методы экологических исследований водоемов Арктики. Мурманск. Изд-во: МГТУ. 2019. 180 с.

4. Страхов Н.М. О сравнительно-литологическом направлении и его ближайших задачах // Бюлл. Моск. о-ва испытателей природы. Отд-е геологии. 1945. № 3-4.

5. Boutron C.F., Candelone J.P., Hong S.M. Greenland snow and ice cores - unique archives of large-scale pollution of the troposphere of the northern-hemisphere by lead and other heavy-metals // Science of the Total Environment. 1995. V. 161. P. 233-241. https://doi.org/10.1016/0048-9697(95)04359-9.

6. Boyle J.F., Rose N.L., Appleby P.G., Birks H.J.B. Recent environmental change and human impact in Svalbard: the lake-sediment geochemical record // Journal of Paleolimnology. 2004. V. 31. P. 515-530. https://doi.org/10.1023/B:JOPL.0000022549.07298.6e.

7. Håkanson L. An ecological risk index for aquatic pollution control - a sedimentological ap-proach // Water Research. 1980. V. 14. P. 975-1001. https://doi.org/10.1016/0043-1354(80)90143-8.

8. Holte B, Dahl S., Gulliksen B. and Næs K. Some macrofaunal effects of local pollution and glacier-induced sedimentation, with indicative chemical analyses, in the sediments of two Arctic fjords // Polar Biology. 1996. V. 16. P. 549-557.

9. $\quad$ Kashulin N.A., Dauvalter V.A., Denisov D.B., Valkova S.A., Vandysh O.I., Terentjev P.M., Kashulin A.N. Selected aspects of the current state of freshwater resources in the Murmansk Region, Russia // Journal of Environmental Science and Health, Part A. 2017. V. 52. No. 9. P. 921-929. https://doi.org/10.1080/1093452 9.2017.1318633.

10. Rognerud S., Skotvold T., Fjeld E., Norton S.A., Hob K.A. Concentrations of trace elements in recent and preindustrial sediments from Norwegian and Russian Arctic lakes // Canadian Journal of Fisheries and Aquatic Science. 1998. V. 55. P. 1512-1523. https://doi.org/10.1139/cjfas-55-6-1512.

11. Rose N.L., Rose C.L., Boyle J.F., Appleby P.G. Lake-sediment evidence for local and remote sources of atmospherically deposited pollutants on Svalbard // Journal of Paleolimnology. 2004. V. 31. P. 499-513. https://doi.org/10.1023/B:JOPL.0000022548.97476.39.

12. Sun Q., Chu G., Liu J., Gao D. A 150-year Record of Heavy Metals in the Varved Sediments of Lake Bolterskardet, Svalbard // Arctic, Antarctic, and Alpine Research. 2006. V. 38. No. 3. P. 436-445. https://doi. org/10.1657/1523-0430(2006)38. 